\title{
Trabalhonecessário
}

Issn: 1808 - 799X

ano 13 , número $20-2015$

\section{TRABALHOS ENCOMENDADOS E MINICURSOS DO GT 09 NO PERÍODO DE 1997 A 2013: ELEMENTOS PARA O DEBATE ${ }^{1}$}

\author{
Georgia Sobreira dos Santos Cêa \\ Sonia Maria Rummert
}

\section{Resumo}

Este texto apresenta reflexões com base no levantamento dos trabalhos encomendados e dos minicursos tratados na programação do GT 09 Trabalho e Educação da Anped no período de $1997^{2}$ a 2013. Objetiva-se, de um lado, recuperar temas privilegiados pelo GT 09 nessas atividades e, de outro, apresentar subsídios para futuras definições de temas para discussão e debate junto aos membros do referido GT.

Palavras-chave: trabalho e educação; GT 09 Trabalho e Educação; Anped.

\begin{abstract}
This text presents some reflections based on the survey of commissioned pieces and short courses treated in the programming of the GT 09 (Work and Education) of Anped from 1997 to 2013. The purpose is, on one side, to recover some privileged themes by GT 09 in these activities and on the other, to contribute to future definition of topics for discussion and debate with the members of this GT.

\footnotetext{
${ }^{1}$ Texto elaborado por Sonia Rummert e Georgia Cêa (respectivamente coordenadora e vicecoordenadora no período de 2012 a 2015) para submissão aos membros do GT 09 Trabalho e Educação da Anped, visando contribuir com os debates internos do referido grupo de trabalho. $O$ texto foi apresentado e debatido no Intercâmbio Nacional de Núcleos de Pesquisa em Trabalho e Educação (II INTERCRÍTICA), ocorrido de 26 a 28 de agosto de 2014 na Universidade Federal do Pará (UFPA).

${ }^{2}$ Segundo Bomfim (2006), é a partir desse ano que a sistemática de trabalhos encomendados e minicursos torna-se orgânica no GT 09.
}

TrabalhoNecessário - www.uff.br/trabalhonecessario; Ano 13, №20/2015. 


\section{Trabalhonecessário}

Issn: 1808 - 799X

ano 13 , número $20-2015$

Key words: Work and Education; GT 09 Work and Education; Anped.

\section{Introdução}

Este texto apresenta reflexões com base no levantamento dos trabalhos encomendados e dos minicursos tratados na programação do GT 09 Trabalho e Educação da Anped no período de $1997^{3}$ a 2013. Objetiva-se, de um lado, recuperar temas privilegiados pelo GT 09 nessas atividades e, de outro, apresentar subsídios para futuras definições de temas para discussão e debate junto aos participantes do referido GT.

Trata-se de um estudo levado a efeito pela coordenação do GT 09 que, sem pretensão de esgotar possibilidades de análise, tem por finalidade contribuir com a tarefa "[...] de amadurecimento do campo científico que pensa sobre seu próprio fazer" (Trein; Ciavatta, 2009, p. 16), conforme outros trabalhos já o fizeram ${ }^{4}$.

As fontes primárias utilizadas foram $C D s$ das reuniões anuais e a programação do GT 09 disponível na página eletrônica da Anped. As informações dos anos de 1997, 1998 e $2002^{5}$ foram extraídas de Bomfim (2006).

Como exercício heurístico, os títulos, ementas e resumos dos trabalhos encomendados e dos minicursos foram analisados e agrupados nas seguintes categorias: fundamentação, metodologia e temas. Deve-se salientar, de antemão, que as categorias ora indicadas não correspondem a campos isolados, de modo que a abordagem teórica, típica do exercício de fundamentação, dialoga com

\footnotetext{
${ }^{3}$ Segundo Bomfim (2006), é a partir desse ano que a sistemática de trabalhos encomendados e minicursos torna-se orgânica no GT 09.

${ }^{4}$ Os trabalhos que tomaram o GT 09 como tema estão indicados no quadro 3 deste texto.

5 Não foi possível ter acesso aos CDs de 1997 e 1998 e as informações sobre trabalho encomendado e minicurso do ano de 2002 não se encontram disponíveis nos demais materiais consultados, por isso a necessidade de consulta à fonte secundária indicada na nota 6 .
}

TrabalhoNecessário - www.uff.br/trabalhonecessario; Ano 13, №20/2015. 
Issn: 1808 - 799X

ano 13 , número $20-2015$

aspectos metodológicos e estabelece mediações com diferentes temas; os aspectos metodológicos, por sua vez, se ancoram em algum tipo de fundamentação e privilegiam temas determinados, os quais, por fim, são tratados com base em fundamentos teórico-metodológicos específicos. A divisão estabelecida para as reflexões expostas neste texto serve, apenas, de indicativo para as discussões a serem empenhadas pelo conjunto do $\mathrm{GT}^{6}$, considerando a natureza da abordagem que vem sendo privilegiada pelo GT 09 nos trabalhos encomendados e minicursos.

O texto tem início com a apresentação de um quadro com o levantamento dos trabalhos encomendados e minicursos no período de 1997 a 2013 e com a sistematização dos dados em forma de gráficos, de modo a permitir a visualização das incidências das categorias no intervalo de tempo considerado. Em seguida, são apresentados apontamentos qualitativos sobre os conteúdos dos trabalhos encomendados e minicursos do GT 09 no período de 1997 a 2013, com base nos títulos e conteúdos a ele subjacentes; neste momento do texto são destacados cinco aspectos considerados mais importantes para a reflexão sobre movimentos futuros do GT 09.

\footnotetext{
${ }^{6}$ Os trabalhos de Arroyo (1981, apud KUENZER, 1991) e Kuenzer (1991) inauguram esta conduta no GT 09. O primeiro sistematiza áreas de pesquisa e de ação: educação e trabalho na política educacional; educação, trabalho e igualdade social; história da relação educação e trabalho no Brasil; função da escola no processo de formação técnica e ética do trabalhador; ciência, educação e processo de produção e trabalho; educação e divisão social do trabalho; educação e formação da classe operária (Árroyo, 1981 apud Kuenzer, 1991). Kuenzer (1991), por sua vez, indica as seguintes áreas temáticas: trabalho e educação - teoria e história; trabalho e educação básica; profissionalização e trabalho; trabalho e educação nos movimentos sociais; educação do trabalhador nas relações sociais de produção. Esses estudos remontam às origens do GT 09 no processo de sua criação e definição de sua identidade. Bomfim (2006), tomando como referência essa identidade, analisa o percurso de constituição do GT 09, com foco no período de 1995 a 2004, destacando os seguintes aspectos: pautas de investigação; pesquisas, perspectivas teóricas e abordagens privilegiadas; escolhas, orientações e encaminhamentos assumidos pelo GT. Trein e Ciavatta $(2003 ; 2009)$ utilizaram as linhas de investigação sintetizadas por Kuenzer para analisar trabalhos selecionados e apresentados no GT 09 nos períodos de 1996 a 2001 (Trein; Ciavatta, 2003) e de 2002 a 2007 (Trein; Ciavatta, 2009). A consulta a tais estudos é fundamental para os interessados na história do GT 09 e na apreensão dos temas e movimentos constitutivos da área temática trabalho e educação.
} 


\section{Trabalhonecessário}

Issn: 1808 - 799X

ano 13 , número $20-2015$

\section{Evidências do levantamento dos trabalhos encomendados e minicursos do GT 09 no período de 1997 a 2013}

O levantamento dos trabalhos encomendados e minicursos é exposto no quadro a seguir:

Quadro 1 - Detalhamento dos trabalhos encomendados e minicursos do GT 09 Trabalho e Educação - 1997-2013

\begin{tabular}{|c|c|c|c|c|}
\hline $\begin{array}{c}\text { Ano / } \\
\text { Coordenaçã } \\
\text { o }\end{array}$ & $\begin{array}{c}\text { Trabalho encomendado } \\
\text { / Autores }\end{array}$ & Categoria & $\begin{array}{c}\text { Minicurso / } \\
\text { Responsáveis }\end{array}$ & Categoria \\
\hline $\begin{array}{l}1997 \\
\text { Caxambu / } \\
20^{\mathrm{a}} \mathrm{RA}^{*} \\
\text { Celso } \\
\text { Ferretti } \\
\text { (PUC-SP) }\end{array}$ & $\begin{array}{l}\text { Trabalho, crise do } \\
\text { trabalho assalariado e do } \\
\text { desenvolvimento da } \\
\text { historicidade do discurso } \\
\text { Gaudêncio Frigotto (UFF) }\end{array}$ & $\begin{array}{l}\text { Fundamentação: } \\
\text { Trabalho e crise }\end{array}$ & $\longrightarrow$ & 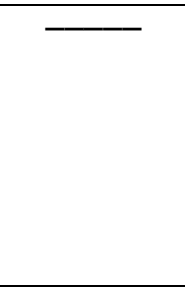 \\
\hline $\begin{array}{l}1998 \\
\text { Caxambu / } \\
21^{\text {a }} \mathrm{RA} \\
\text { Celso } \\
\text { Ferretti } \\
\text { (PUC-SP) }\end{array}$ & $\begin{array}{l}\text { A formação humana } \\
\text { integral para uma } \\
\text { socioeconomia solidária: } \\
\text { uma práxis superadora } \\
\text { Marcos Arruda (IPACS / } \\
\text { Instituto Transnacional de } \\
\text { Amsterdã) } \\
\text { A política de formação } \\
\text { técnico-profissional, } \\
\text { globalização excludente } \\
\text { e desemprego } \\
\text { estrutural } \\
\text { Gaudêncio Frigotto (UFF) }\end{array}$ & $\begin{array}{l}\text { Tema: Formação } \\
\text { humana e } \\
\text { economia solidária } \\
\text { Tema: Política de } \\
\text { formação técnico- } \\
\text { profissional }\end{array}$ & 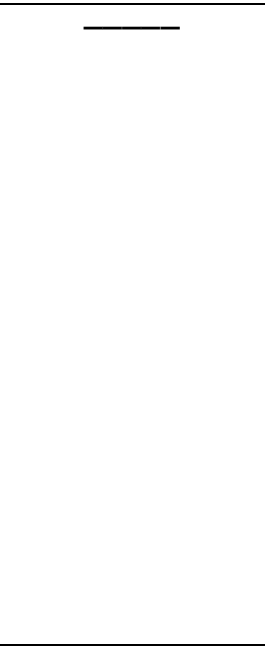 & $\bar{T}$ \\
\hline $\begin{array}{l}1999 \\
\text { Caxambu / } \\
22^{a} \text { RA* }^{*} \\
\text { Lucília } \\
\text { Machado } \\
\text { (UFMG) }\end{array}$ & $\begin{array}{l}\text { Economia da educação X } \\
\text { Economicismo } \\
\text { Claudio Salm (UFJF) } \\
\text { Os horizontes se } \\
\text { ampliam ou restringem- } \\
\text { se? Desafios para a }\end{array}$ & $\begin{array}{l}\text { Fundamentação: } \\
\text { Economia da } \\
\text { educação } \\
\text { Metodologia: } \\
\text { Categoria trabalho } \\
\text { e implicações no } \\
\end{array}$ & & \\
\hline
\end{tabular}

\footnotetext{
7 As fontes primárias utilizadas foram os CDs das reuniões anuais e a programação do GT 09 disponível na página eletrônica da Anped. As informações dos anos de 1997, 1998 e 2002 foram extraídas de Bomfim (2006).
}

TrabalhoNecessário - www.uff.br/trabalhonecessario; Ano 13, №20/2015. 


\section{Trabalhonecessário}

Issn: 1808 - 799X

ano 13 , número $20-2015$

\begin{tabular}{|c|c|c|c|c|}
\hline & $\begin{array}{l}\text { investigação no campo } \\
\text { da educação a partir da } \\
\text { categoria trabalho } \\
\text { Iracy Picanço (UFBA) }\end{array}$ & $\begin{array}{l}\text { campo da } \\
\text { educação }\end{array}$ & & \\
\hline $\begin{array}{l}2000 \\
\text { Caxambu / } \\
23^{-2} \text { RA } \\
\text { Lucília } \\
\text { Machado } \\
\text { (UFMG) }\end{array}$ & $\begin{array}{l}\text { Trabalho e Educação: } \\
\text { desafios teóricos e } \\
\text { problemas conceituais e } \\
\text { metodológicos } \\
\text { Gaudêncio Frigotto (UFF) }\end{array}$ & $\begin{array}{l}\text { Metodologia: } \\
\text { Conceitos e } \\
\text { implicações } \\
\text { metodológicas da } \\
\text { relação trabalho e } \\
\text { educação }\end{array}$ & $\begin{array}{l}\text { Interdisciplinaridad } \\
\text { e, } \\
\text { transdisciplinaridad } \\
\text { e e sociedade do } \\
\text { conhecimento: } \\
\text { produção do } \\
\text { conhecimento e } \\
\text { produção da } \\
\text { existência } \\
\text { Ari Paulo Jantsch } \\
\text { (UFSC) / Lucídio } \\
\text { Bianchetti (UFSC) }\end{array}$ & $\begin{array}{l}\text { Metodologia: } \\
\text { Interdisicplinaridade }\end{array}$ \\
\hline $\begin{array}{l}2001 \\
\text { Caxambu / } \\
\text { 24를 RA } \\
\text { Paulo Sergio } \\
\text { Tumolo (UFS } \\
\text { C) }\end{array}$ & $\begin{array}{l}\text { O trabalho e seus } \\
\text { sentidos: teses e } \\
\text { polêmicas contra a } \\
\text { desconstrução do } \\
\text { trabalho } \\
\text { Ricardo Antunes (Unicam } \\
\text { p) }\end{array}$ & $\begin{array}{l}\text { Fundamentação: } \\
\text { Centralidade do } \\
\text { trabalho }\end{array}$ & $\begin{array}{l}\text { O pensamento } \\
\text { pedagógico } \\
\text { empresarial no } \\
\text { Brasil: do } \\
\text { industrialismo à } \\
\text { competitividade } \\
\text { José dos } \\
\text { Santos Rodrigues ( } \\
\text { UFF) }\end{array}$ & Tema: Empresários \\
\hline $\begin{array}{l}2002 \\
\text { Caxambu / } \\
25^{\mathrm{a}} \mathrm{RA}^{*}\end{array}$ & $\begin{array}{l}\text { Trabalho e educação - } \\
\text { uma análise para debate } \\
\text { Maria Ciavatta (UFF) / } \\
\text { Eunice Trein (UFF) } \\
\text { Trabalho e Educação na } \\
\text { produção acadêmica dos } \\
\text { núcleos de pesquisa } \\
\text { Lucília Machado (UFMG) }\end{array}$ & $\begin{array}{l}\text { Fundamentação: } \\
\text { Percurso do GT } \\
\text { Fundamentação: } \\
\text { Percurso do GT }\end{array}$ & $\begin{array}{l}\text { A pesquisa } \\
\text { educacional e o } \\
\text { uso de imagens } \\
\text { Maria Ciavatta } \\
\text { Franco (UFF) / } \\
\text { Nilda Alves (UERJ) } \\
\text { / Gustavo } \\
\text { Fischman }\end{array}$ & $\begin{array}{l}\text { Metodologia: Uso de } \\
\text { imagens }\end{array}$ \\
\hline $\begin{array}{l}2003 \\
\text { Poços de } \\
\text { Caldas / 26a } \\
\text { RA } \\
\text { Maria } \\
\text { Ciavatta } \\
\text { (UFF) }\end{array}$ & $\begin{array}{l}\text { Emprego, trabalho e } \\
\text { alternativas de economia } \\
\text { popular e solidária } \\
\text { José Carlos Assis (UFRJ) } \\
\text { / Antonio David Cattani } \\
\text { (UFRGS) / Iracy Picanço } \\
\text { (UFBA) }\end{array}$ & $\begin{array}{l}\text { Tema: Economia } \\
\text { popular e solidária }\end{array}$ & $\begin{array}{l}\text { Crise do capital e } \\
\text { implicações } \\
\text { teórico- } \\
\text { metodológicas na } \\
\text { relação trabalho e } \\
\text { educação } \\
\text { Gaudêncio Frigotto } \\
\text { (UFF) e Sônia } \\
\text { Maria Rummert } \\
\text { (UFF) }\end{array}$ & $\begin{array}{l}\text { Metodologia: Crise } \\
\text { capitalista }\end{array}$ \\
\hline $\begin{array}{l}2004 \\
\text { Caxambu / }\end{array}$ & $\begin{array}{l}\text { Politecnia ou educação } \\
\text { tecnológica: desafios ao }\end{array}$ & $\begin{array}{l}\text { Fundamentação: } \\
\text { Politecnia }\end{array}$ & $\begin{array}{l}\text { Trabalho e } \\
\text { educação face às }\end{array}$ & $\begin{array}{l}\text { Fundamentação: } \\
\text { Mudanças no }\end{array}$ \\
\hline
\end{tabular}

TrabalhoNecessário - www.uff.br/trabalhonecessario; Ano 13, №20/2015. 


\section{Trabalhonecessário}

Issn: 1808 - 799X

ano 13 , número $20-2015$

\begin{tabular}{|c|c|c|c|c|}
\hline $\begin{array}{l}27^{\text {a }} \text { RA } \\
\text { Maria } \\
\text { Ciavatta } \\
\text { (UFF) }\end{array}$ & $\begin{array}{l}\text { ensino médio e à } \\
\text { educação profissional } \\
\\
\text { Domingos Leite Lima } \\
\text { Filho (CEFET-Pr) / Nilson } \\
\text { Dias Garcia (CEFET-Pr) }\end{array}$ & & $\begin{array}{l}\text { novas bases } \\
\text { técnicas e culturais } \\
\text { do trabalho } \\
\text { Ramon Peña } \\
\text { Castro (UFSCar) }\end{array}$ & mundo do trabalho \\
\hline $\begin{array}{l}2005 \\
\text { Caxambu / } \\
28^{\text {a }} \mathrm{RA} \\
\text { Marlene } \\
\text { Ribeiro } \\
\text { (UFRGS) }\end{array}$ & $\begin{array}{l}\text { Políticas e reformas do } \\
\text { ensino médio e } \\
\text { profissional: concepções } \\
\text { e práticas } \\
\text { Aparecida de Fátima } \\
\text { Tiradentes dos Santos } \\
\text { (FIOCRUZ)* }\end{array}$ & $\begin{array}{l}\text { Tema: Ensino } \\
\text { médio e } \\
\text { profissional }\end{array}$ & $\begin{array}{l}\text { Introdução ao } \\
\text { estudo do capital } \\
\text { Paulo Sergio } \\
\text { Tumolo (UFSC) }\end{array}$ & $\begin{array}{l}\text { Fundamentação: } \\
\text { Leitura de O capital }\end{array}$ \\
\hline $\begin{array}{l}2006 \\
\text { Caxambu / } \\
29^{2} \text { RA } \\
\text { Marlene } \\
\text { Ribeiro } \\
\text { (UFRGS) }\end{array}$ & $\begin{array}{l}\text { Trabalho e educação: } \\
\text { fundamentos ontológicos } \\
\text { e históricos } \\
\text { Dermeval Saviani } \\
\text { (UNICAMP) }\end{array}$ & $\begin{array}{l}\text { Fundamentação: } \\
\text { Trabalho e } \\
\text { educação }\end{array}$ & $\begin{array}{l}\text { O método da } \\
\text { Economia Política } \\
\text { Maria Ciavatta } \\
\text { Franco (UFF) / } \\
\text { Eunice Trein (UFF) }\end{array}$ & $\begin{array}{l}\text { Metodologia: } \\
\text { Economia política }\end{array}$ \\
\hline $\begin{array}{l}2007 \\
\text { Caxambu / } \\
30^{\mathrm{a}} \mathrm{RA} \\
\\
\text { Ronaldo } \\
\text { Marcos de } \\
\text { Lima Araújo } \\
\text { (UFPA) }\end{array}$ & $\begin{array}{l}\text { A relação trabalho e } \\
\text { educação e os sentidos } \\
\text { do trabalho } \\
\text { Acácia } \\
\text { Zeneida Kuenzer (UFPR) }\end{array}$ & $\begin{array}{l}\text { Fundamentação: } \\
\text { Relação trabalho e } \\
\text { educação }\end{array}$ & $\begin{array}{l}\text { Trabalho, Estado e } \\
\text { educação em } \\
\text { Antonio Gramsci } \\
\text { Paolo Nosella } \\
\text { (UFSCar / } \\
\text { UNINOVE) }\end{array}$ & $\begin{array}{l}\text { Fundamentação: } \\
\text { Gramsci }\end{array}$ \\
\hline $\begin{array}{l}2008 \\
\text { Caxambu / } \\
31^{\text {a }} \mathrm{RA} \\
\\
\text { Ronaldo } \\
\text { Marcos de } \\
\text { Lima Araújo } \\
\text { (UFPA) }\end{array}$ & $\begin{array}{l}\text { A polissemia do trabalho } \\
\text { Gaudêncio Frigotto } \\
\text { (UERJ) / Lucília Machado } \\
\text { (UNA) }\end{array}$ & $\begin{array}{l}\text { Fundamentação: } \\
\text { Conceito de } \\
\text { trabalho }\end{array}$ & $\begin{array}{l}\text { O princípio do } \\
\text { trabalho na } \\
\text { História da } \\
\text { Educação } \\
\text { Marisa Bittar } \\
\text { (UFSCar) / } \\
\text { Amarílio Ferreira } \\
\text { Júnior (UFSCar) }\end{array}$ & $\begin{array}{l}\text { Fundamentação: } \\
\text { Trabalho e história } \\
\text { da educação }\end{array}$ \\
\hline $\begin{array}{l}2009 \\
\text { Caxambu / } \\
32^{\text {a }} \text { RA } \\
\text { Marise } \\
\text { Nogueira } \\
\text { Ramos } \\
\text { (UERJ) }\end{array}$ & $\begin{array}{l}\text { Compreensão teórica e } \\
\text { histórica da crise } \\
\text { contemporânea e seus } \\
\text { desdobramentos no } \\
\text { mundo do trabalho e da } \\
\text { educação } \\
\text { Armando Boito Júnior } \\
\text { (UNICAMP) }\end{array}$ & $\begin{array}{l}\text { Fundamentação: } \\
\text { Crise do capital }\end{array}$ & $\begin{array}{l}\text { Anarquismo, } \\
\text { escola e trabalho: } \\
\text { o emergir da } \\
\text { memória por meio } \\
\text { do Arquivo João } \\
\text { Penteado } \\
\text { Carmen Sylvia } \\
\text { Vidigal Moraes } \\
\text { (USP) / Doris } \\
\text { Accioly e Silva } \\
\text { (USP) }\end{array}$ & $\begin{array}{l}\text { Fundamentação: } \\
\text { Anarquismo }\end{array}$ \\
\hline $\begin{array}{l}2010 \\
\text { Caxambu / }\end{array}$ & $\begin{array}{l}\text { O trabalho docente frente } \\
\text { ao produtivismo }\end{array}$ & $\begin{array}{l}\text { Tema: Trabalho } \\
\text { docente e }\end{array}$ & $\begin{array}{l}\text { História e } \\
\text { historiografia em }\end{array}$ & $\begin{array}{l}\text { Metodologia: } \\
\text { História e }\end{array}$ \\
\hline
\end{tabular}

TrabalhoNecessário - www.uff.br/trabalhonecessario; Ano 13, №20/2015. 


\section{Trabalhonecessário}

Issn: 1808 - 799X

ano 13, número $20-2015$

\begin{tabular}{|c|c|c|c|c|}
\hline $\begin{array}{l}3^{\mathrm{a}} \mathrm{RA} \\
\text { Marise } \\
\text { Nogueira } \\
\text { Ramos } \\
\text { (UERJ) }\end{array}$ & $\begin{array}{l}\text { acadêmico: } \\
\text { constrangimentos e } \\
\text { perspectivas de } \\
\text { enfrentamento } \\
\text { Eunice Trein (UFF) / José } \\
\text { Rodrigues (UFF) }\end{array}$ & $\begin{array}{l}\text { produtivismo } \\
\text { acadêmico }\end{array}$ & $\begin{array}{l}\text { trabalho e } \\
\text { educação } \\
\text { Maria Ciavatta } \\
\text { (UFF) }\end{array}$ & historiografia \\
\hline $\begin{array}{l}2011 \\
\text { Natal / 34 } \\
\text { RA } \\
\text { Maria Clara } \\
\text { Bueno } \\
\text { Fischer } \\
\text { (UFRGS) }\end{array}$ & $\begin{array}{l}\text { A realidade do trabalho } \\
\text { hoje: continuidades e } \\
\text { descontinuidades no } \\
\text { atual estágio do } \\
\text { capitalismo. } \\
\text { Consequências na } \\
\text { educação formal e na } \\
\text { formação humana em } \\
\text { geral } \\
\text { Marcio Pochmann } \\
\text { (UNICAMP) / Sônia Maria } \\
\text { Rummert (UFF) }\end{array}$ & $\begin{array}{l}\text { Fundamentação: } \\
\text { Capitalismo e } \\
\text { formação humana }\end{array}$ & $\begin{array}{l}\text { Trabalho, classes } \\
\text { sociais e } \\
\text { experiência } \\
\text { histórica na obra } \\
\text { de E. P. Thompson } \\
\text { Célia Regina } \\
\text { Vendramini } \\
\text { (UFSC) / Lia Tiriba } \\
\text { (UFF) }\end{array}$ & $\begin{array}{l}\text { Fundamentação: } \\
\text { Thompson }\end{array}$ \\
\hline $\begin{array}{l}2012 \\
\text { Porto de } \\
\text { Galinhas / } \\
\text { 35a RA } \\
\text { Maria Clara } \\
\text { Bueno } \\
\text { Fischer } \\
\text { (UFRGS) }\end{array}$ & $\begin{array}{l}\text { Politecnia e formação } \\
\text { integrada: confrontos } \\
\text { conceituais, projetos } \\
\text { políticos } \\
\text { e contradições históricas } \\
\text { da educação brasileira } \\
\\
\text { Dante Henrique Moura } \\
\text { (IFRN) / Domingos Leite } \\
\text { Lima Filho (UTFPR) / } \\
\text { Mônica Ribeiro da Silva } \\
\text { (UFPR) }\end{array}$ & $\begin{array}{l}\text { Fundamentação: } \\
\text { Politecnia e } \\
\text { formação } \\
\text { integrada }\end{array}$ & $\begin{array}{l}\text { Trabalho, práxis e } \\
\text { a construção da } \\
\text { identidade teórico- } \\
\text { metodológica do } \\
\text { GT Trabalho e } \\
\text { Educação } \\
\text { Justino de Sousa } \\
\text { Junior (UFC) }\end{array}$ & $\begin{array}{l}\text { Fundamentação: } \\
\text { Identidade do GT }\end{array}$ \\
\hline 2013 & $\begin{array}{l}\text { Trabalho educação e } \\
\text { movimentos sociais } \\
\text { Iracy Picanço (UFBA) / } \\
\text { Roseli Salete Caldart } \\
\text { (ITERRA) }\end{array}$ & $\begin{array}{l}\text { Fundamentação: } \\
\text { Trabalho e } \\
\text { educação e } \\
\text { movimentos } \\
\text { sociais }\end{array}$ & $\begin{array}{l}\text { Materialismo } \\
\text { histórico, trabalho, } \\
\text { educação e } \\
\text { movimentos } \\
\text { sociais: desafios } \\
\text { de pesquisa } \\
\text { Conceição Paludo } \\
\text { (UFPel) }\end{array}$ & $\begin{array}{l}\text { Metodologia: } \\
\text { Materialismo } \\
\text { histórico }\end{array}$ \\
\hline
\end{tabular}

*Obs: Trabalho não apresentado por impossibilidade da presença da pesquisadora à reunião.

Organizando os trabalhos encomendados e minicursos em categorias fundamentação; metodologia; temas -, chega-se ao seguinte:

Quadro 2 - Trabalhos e minicursos do GT 09 Trabalho e Educação, segundo a categoria 1997-2013

\begin{tabular}{|c|c|c|}
\hline Ano & Trabalhos encomendados & Minicursos \\
\hline
\end{tabular}

TrabalhoNecessário - www.uff.br/trabalhonecessario; Ano 13, №20/2015. 


\section{Trabalhonecessário}

Issn: 1808 - 799X

ano 13, número $20-2015$

\begin{tabular}{|c|l|l|}
\hline 1997 & Fundamentação: Trabalho e crise & \\
\hline 1998 & $\begin{array}{l}\text { Tema: Formação humana e economia solidária } \\
\text { Tema: Política de formação técnico-profissional }\end{array}$ & \\
\hline 1999 & $\begin{array}{l}\text { Fundamentação: Economia da educação } \\
\text { Metodologia: Categoria trabalho e implicações no } \\
\text { campo da educação }\end{array}$ & \\
\hline 2000 & $\begin{array}{l}\text { Metodologia:Conceitos e implicações metodológicas } \\
\text { da relação trabalho e educação }\end{array}$ & Metodologia: Interdisciplinaridade \\
\hline 2001 & Fundamentação: Centralidade do trabalho & Tema: Empresários \\
\hline 2002 & $\begin{array}{l}\text { Fundamentação: Percurso do GT } \\
\text { Fundamentação: Percurso do GT }\end{array}$ & Metodologia: Uso de imagens \\
\hline 2003 & Tema: Economia popular e solidária & Metodologia: Crise capitalista \\
\hline 2004 & Fundamentação: Politecnia & $\begin{array}{l}\text { Fundamentação: Mudanças no } \\
\text { mundo do trabalho }\end{array}$ \\
\hline 2005 & Tema: Ensino médio e profissional & $\begin{array}{l}\text { Fundamentação: Leitura de O } \\
\text { capital }\end{array}$ \\
\hline 2006 & Fundamentação: Trabalho e educação & Metodologia: Economia política \\
\hline 2007 & Fundamentação: Relação trabalho e educação & Fundamentação: Gramsci \\
\hline 2008 & Fundamentação: Conceito de trabalho & $\begin{array}{l}\text { Fundamentação: Trabalho e } \\
\text { história da educação }\end{array}$ \\
\hline 2009 & Fundamentação: Crise do capital & Fundamentação: Anarquismo \\
\hline 2010 & Tema: Trabalho docente e produtivismo acadêmico & $\begin{array}{l}\text { Metodologia: História e } \\
\text { historiografia }\end{array}$ \\
\hline 2011 & Fundamentação: Capitalismo e formação humana & Fundamentação: Thompson \\
\hline 2012 & Fundamentação:Politecnia e formação integrada & $\begin{array}{l}\text { Fundamentação: Identidade do } \\
\text { GT }\end{array}$ \\
\hline 2013 & $\begin{array}{l}\text { Fundamentação: Trabalho e educação e movimentos } \\
\text { sociais }\end{array}$ & $\begin{array}{l}\text { Metodologia: Materialismo } \\
\text { histórico }\end{array}$ \\
\hline
\end{tabular}

É clara a prevalência de trabalhos encomendados e minicursos que objetivam discutir a fundamentação teórica da área trabalho e educação, conforme ilustram os gráficos 1 e 2 a seguir, considerando a distribuição das categorias nos trabalhos encomendados e nos minicursos, respectivamente:

\section{Gráfico 1 - Distribuição das categorias nos trabalhos encomendados - Quantidade e percentual - 1997 a 2013}




\section{Trabalhonecessário}

Issn: 1808 - 799X

ano 13, número $20-2015$

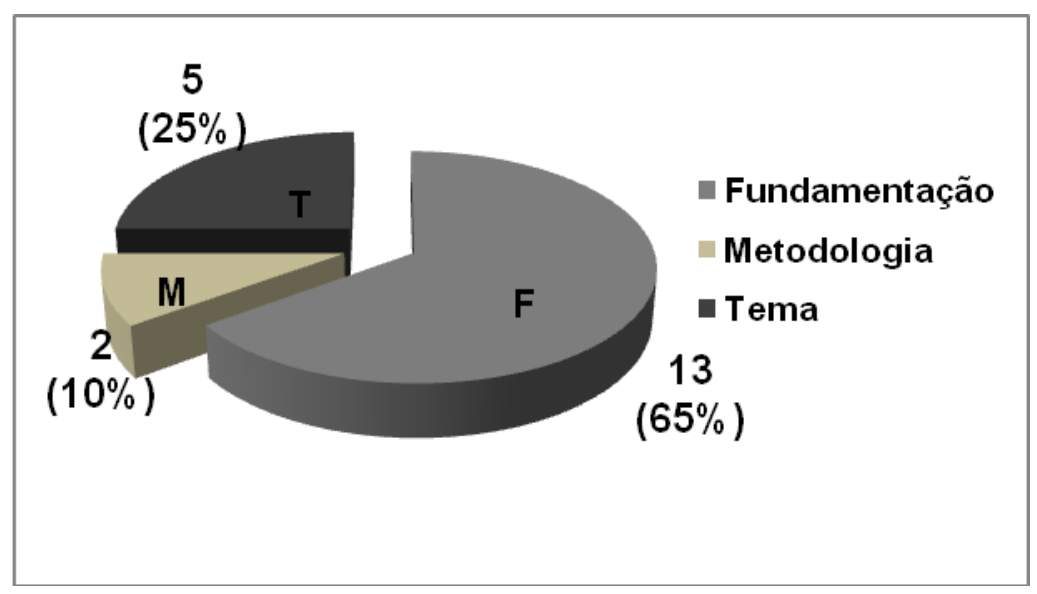

Gráfico 2 - Distribuição das categorias nos minicursos - Quantidade e percentual - 1997 a 2013

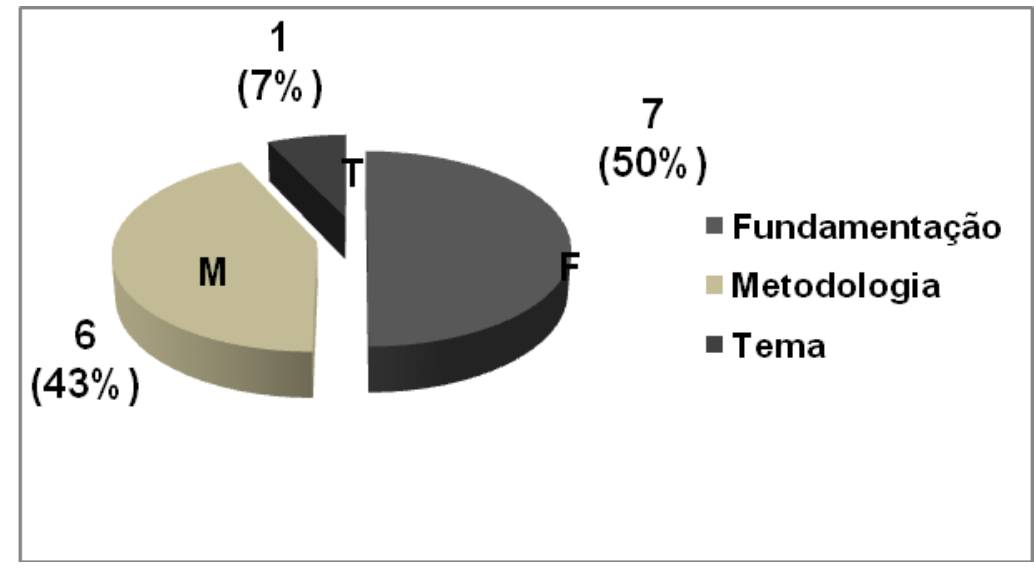

A distribuição das categorias tratadas nos trabalhos encomendados e nos minicursos indica que essa atividade do GT tende a abrigar, predominantemente, conteúdos afetos à fundamentação da área. Nos minicursos, mais do que nos trabalhos encomendados, os temas de fundamentação teórica dividem importância com questões relativas à metodologia. Os temas específicos, por sua vez, recebem menos destaque nos minicursos - uma incidência no período analisado - e ocupam a segunda posição entre as categorias privilegiadas nos trabalhos encomendados. Isso indica o que Bomfim (2006, p. 112) denominou de "vocação teórica do grupo". 


\section{Trabalhonecessário}

Issn: 1808 - 799X

ano 13 , número $20-2015$

Os dados expostos sobre os conteúdos dos trabalhos encomendados e minicursos do GT 09 entre 1997 e 2013 indicam a predominância da categoria fundamentação, seguida de metodologia e temas. Isso evidencia claramente a tendência do GT em priorizar discussões de caráter teórico-metodológico nos momentos da programação que permitem autonomia aos seus membros, visto que eles definem os trabalhos encomendados e os minicursos ${ }^{8}$. O gráfico 3 , a seguir, ilustra, em conjunto, a distribuição das categorias nos trabalhos encomendados e nos minicursos:

\section{Gráfico3 - Distribuição das categorias nos trabalhos encomendados e nos minicursos -}

Quantidade e percentual - 1997 a 2013

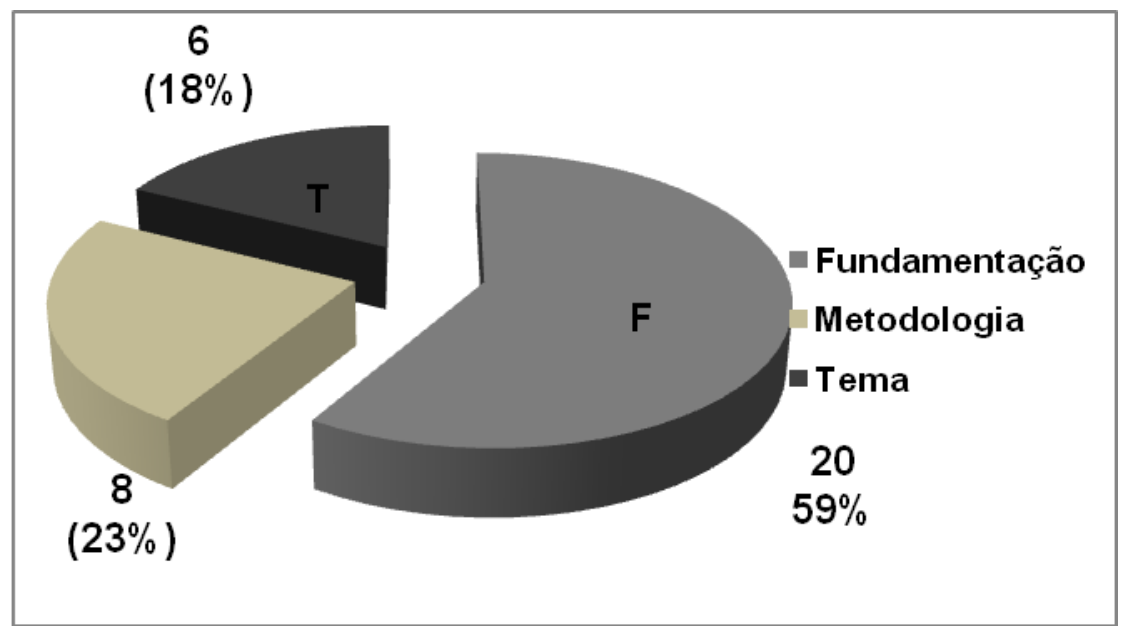

Com base nesse levantamento e em suas evidências são indicadas, no tópico a seguir, questões qualitativas acerca dos conteúdos identificados.

\section{Apontamentos qualitativos sobre os conteúdos dos trabalhos encomendados e minicursos do GT 09 no período de 1997 a 2013}

\footnotetext{
${ }^{8}$ As formas e os momentos dessa definição podem variar, dependendo da dinâmica dos GTs da Anped. No caso do GT 09, desde 2003 os trabalhos encomendados, os minicursos e as sessões especiais são propostos pelas coordenações via e-mail do grupo, com base nas discussões e debates ocorridos na reunião anterior. Em 2015, estão associados ao grupo 310 participantes, os quais trocam informações por essa via, Incluindo mensagens enviadas pela coordenação.
}

TrabalhoNecessário - www.uff.br/trabalhonecessario; Ano 13, №20/2015. 


\section{Trabalhonecessário}

Issn: 1808 - 799X

ano 13 , número $20-2015$

A partir dos conteúdos dos trabalhos encomendados, é possível indicar o seguinte:

a) Cinco conjuntos de conteúdos referentes à categoria fundamentação:

- Trabalho e crise do capital (expresso nos conteúdos trabalho e crise;centralidade do trabalho; conceito de trabalho;crise do capital);

- Fundamentos da relação trabalho e educação (expresso nos conteúdos economia da educação; trabalho e educação; relação trabalho e educação);

- Formação humana (expresso nos conteúdos politecnia; capitalismo e formação humana; politecnia e formação integrada);

- Identidade do GT 09 (expresso no conteúdo percurso do GT).

- Movimentos sociais (expresso no conteúdo trabalho e educação e movimentos sociais)

b) Um conjunto de conteúdos referentes à categoria metodologia:

- Desafios teórico-metodológicos da área trabalho e educação (expresso nos conteúdos investigação no campo da educação a partir da categoria trabalho;categoria trabalho e implicações no campo da educação).

c) Três conjuntos de conteúdos referentes à categoria temas:

- Economia solidária (expresso nos conteúdos formação humana e economia solidária; economia popular e solidária);

- Formação profissional (expresso nos conteúdos política de formação técnicoprofissional; ensino médio e profissional);

- Trabalho docente (expresso no conteúdo trabalho docente e produtivismo acadêmico).

O mesmo exercício aplicado aos minicursos resulta no seguinte:

a) Três conjuntos de conteúdos referentes à categoria fundamentação:

- Arcabouços teórico-metodológicos clássicos da área trabalho e educação (expresso nos conteúdos leitura de O capital; Gramsci; anarquismo; Thompson); 


\section{Trabalhonecessário}

Issn: 1808 - 799X

ano 13 , número $20-2015$

- Desafios teórico-metodológicos contemporâneos da área trabalho e educação (expresso nos conteúdos mudanças no mundo do trabalho; trabalho e história da educação);

- Identidade do GT 09 (expresso no conteúdo identidade do GT).

b) Dois conjuntos de conteúdos referentes à categoria metodologia:

- Arcabouço metodológico clássico (expresso nos conteúdos economia política; crise capitalista);

- Aportes metodológicos contemporâneos (expresso nos conteúdos interdisciplinaridade; uso de imagens; história e historiografia; materialismo histórico e movimentos sociais).

c) Um conteúdo referente à categoria tema (expresso no conteúdo empresários).

Sem a pretensão de esgotar possibilidades interpretativas e analíticas, são indicados, a seguir, cinco aspectos considerados mais importantes para a reflexão sobre movimentos futuros do GT 09. Os dois primeiros pretendem assinalar elementos a serem reafirmados no movimento do GT; os três seguintes pretendem indicar questões a serem avaliadas e consideradas, se pertinentes. São eles:

1) Com base nos conjuntos de conteúdos apresentados anteriormente, é possível identificar, de forma ampla, o movimento interno na dinâmica dos trabalhos encomendados e dos minicursos de se considerar conteúdos clássicos, de marca explicitamente marxista, e conteúdos contemporâneos, que traduzem questões que afetam diretamente a área trabalho e educação, abarcando inúmeras dimensões teórico-metodológicas. Tal movimento parece constituir o elemento identitário mais profícuo do GT, visto que indica a pretensão de adensamento e atualização dos conteúdos basilares e emergentes afetos à área. Indicando a especificidade da área frente a outras, Kuenzer (1991, p. 92) afirma que a educação é pensada a partir da retomada dos "[...] princípios fundamentais da crítica à economia política [...]", de modo 


\section{Trabalhonecessário}

Issn: 1808 - 799X

ano 13 , número $20-2015$

que a identidade do GT se deve ao fato que [...] a dimensão trabalho constituise como categoria central da qual se parte para a compreensão do fenômeno educativo e das articulações recíprocas entre estas duas dimensões educação e trabalho (Kuenzer, 1991, p. 92). As categorias identificadas na análise dos conteúdos dos trabalhos encomendados e dos minicursos afirmam essa forma de tratamento da relação trabalho e educação.

2) Verifica-se que inúmeros conteúdos tratados nos trabalhos encomendados e nos minicursos constituem, ao mesmo tempo, campos de interesse do GT 09 e objetos de investigação de seus membros. Estes, em especial, encontram nos minicursos espaços predominantes de socialização e debate de estudos/pesquisas no GT, onde é possível tratá-los de forma mais aprofundada do que se fossem apresentados como trabalhos submetidos à Anped e inseridos na programação do GT 09.Neste tópico, é significativo também o fato de que a expressiva maioria dos responsáveis pelos trabalhos encomendados e minicursos indicados pelo GT - como se observa no quadro 1 - é composta por seus membros efetivos e atuantes, havendo, especialmente a partir da década de 2000 , variação dos nomes definidos. Isso indica a vitalidade e a capacidade de produção de conhecimento dos membros do GT, condições que podem ser ampliadas; ao mesmo tempo, o convite extensivo a pesquisadores de outras áreas do conhecimento indica a abertura a diálogos com campos do conhecimento e com pesquisadores mediatamente vinculados ao GT 09.

3) Um aspecto geral a ser destacado é o fato de nem sempre haver uma articulação orgânica entre os temas definidos para 0 trabalho encomendado e para os minicursos, o que, se acontecesse, poderia ampliar a capacidade formativa do GT para os seus participantes, especialmente nos momentos da reunião que podem ser deliberados pelo conjunto dos membros do GT. 


\section{Trabalhonecessário}

Issn: 1808 - 799X

ano 13, número $20-2015$

4) $O$ fato de a formação humana e de seus fundamentos ter espaço significativo entre os conteúdos dos trabalhos encomendados pode indicar que há forte preocupação do GT 09 com a afirmação do referencial teórico marxista como aquele capaz de contribuir com práticas formativas ética e politicamente comprometidas com a perspectiva da classe trabalhadora, na direção da superação da sociedade capitalista. Entretanto, nas ocasiões em que a realidade objetiva foi tomada como objeto dos trabalhos, se privilegiou a formação profissional como momento e/ou forma precípuos da formação humana sustentada. A ampliação do escopo da identificação e compreensão dos modos, espaços, tempos e sujeitos envolvidos nos processos de formação humana, formais e não formais, aparece como uma necessidade ainda não amadurecida no GT.Nessa direção, por exemplo, foram definidos os temas do trabalho encomendado e do minicurso da reunião de 2013 (Trabalho, educação e movimentos sociais; Materialismo histórico, trabalho, educação e movimento sociais: desafios de pesquisa, respectivamente).

5) No período analisado, a identidade do GT foi conteúdo de dois momentos: trabalho encomendado, em 2002, e minicurso, em 2012. Esses únicos momentos contrastam, entretanto, com a importância do GT 09 como objeto de análise de inúmeros estudos, indicados no quadro a seguir?:

Quadro 3 - Trabalhos publicados sobre o percurso do GT 09 Trabalho e Educação $1987 / 2013$

\begin{tabular}{|c|l|l|l|}
\hline Ano & Autor(es) & \multicolumn{1}{|c|}{ Título } & \multicolumn{1}{c|}{ Publicação } \\
\hline 1981 & Miguel Arroyo & Educação e Trabalho & $\begin{array}{l}\text { Reunião Anual da } \\
\text { Associação Nacional } \\
\text { de Pós-Graduação e } \\
\text { Pesquisa em Educação. } \\
\end{array}$ \\
& & & \begin{tabular}{l} 
Rio de Janeiro: ANPED, \\
\hline
\end{tabular}
\end{tabular}

${ }^{9} \mathrm{O}$ conteúdo e as conclusões dos estudos em questão não são tomados como referências neste texto, visto seu objetivo marcadamente indicativo. O quadro 3 serve, aqui, de fundamentação da argumentação apresentada no item 5 , podendo assumir a feição de roteiro indicativo para os interessados em se apropriarem do percurso do GT 09 ao longo do tempo.

TrabalhoNecessário - www.uff.br/trabalhonecessario; Ano 13, №20/2015. 


\section{Trabalhonecessário}

Issn: 1808 - 799X

ano 13 , número $20-2015$

\begin{tabular}{|c|c|c|c|}
\hline & & & 1981. \\
\hline 1987 & Acácia Kuenzer & $\begin{array}{l}\text { Educação e trabalho no Brasil: o } \\
\text { estado da questão }\end{array}$ & $\begin{array}{l}\text { Brasília: INEP/MEC, } \\
1987^{* \star} \text {. }\end{array}$ \\
\hline 1995 & $\begin{array}{l}\text { Eunice Trein; Iracy } \\
\text { Picanço }\end{array}$ & O GT Trabalho e Educação & $\begin{array}{l}\text { Histórico dos grupos de } \\
\text { trabalho. Belo } \\
\text { Horizonte: ANPEd. } \\
1995 .\end{array}$ \\
\hline $1996^{*}$ & Eunice Trein & $\begin{array}{l}\text { A pesquisa na área trabalho e } \\
\text { educação }\end{array}$ & $\begin{array}{l}\text { Curitiba: UFPR } \\
\text { (mimeo.), } 1996 .\end{array}$ \\
\hline $1997^{*}$ & $\begin{array}{l}\text { Eneida Shiroma; } \\
\text { Roselane F. Campos }\end{array}$ & $\begin{array}{l}\text { Qualificação e reestruturação } \\
\text { produtiva: um balanço das pesquisas } \\
\text { em educação }\end{array}$ & $\begin{array}{l}\text { Educação \& Sociedade, } \\
\text { Campinas, CEDES, nº } \\
61, \text { p. 13-35, dez. }\end{array}$ \\
\hline 2003 & $\begin{array}{l}\text { Eunice Trein; Maria } \\
\text { Ciavatta }\end{array}$ & $\begin{array}{l}\text { O percurso teórico e empírico do GT } \\
\text { Trabalho e Educação: uma análise } \\
\text { para debate }\end{array}$ & $\begin{array}{l}\text { Revista Brasileira de } \\
\text { Educação, n. 24, } \\
\text { set./dez., 2003, p. 140- } \\
164 .\end{array}$ \\
\hline 2006 & $\begin{array}{l}\text { Alexandre Maia do } \\
\text { Bomfim }\end{array}$ & $\begin{array}{l}\text { Desvendando a área de Trabalho e } \\
\text { Educação: estudo sobre a produção e } \\
\text { os produtores do GT Trabalho e } \\
\text { Educação da Anped }\end{array}$ & $\begin{array}{l}\text { Tese de doutorado - } \\
\text { PUC-Rio, } 2006 .\end{array}$ \\
\hline $2008^{*}$ & $\begin{array}{l}\text { Monica Ribeiro da } \\
\text { Silva }\end{array}$ & $\begin{array}{l}\text { Trabalho e educação: aportes da linha } \\
\text { de pesquisa para o estudo do trabalho } \\
\text { escolar }\end{array}$ & $\begin{array}{l}\text { Trabalho \& Educação. } \\
\text { v.17, n. 1, jan./abr. } \\
2008 .\end{array}$ \\
\hline 2008 & $\begin{array}{l}\text { Alexandre Maia do } \\
\text { Bomfim }\end{array}$ & $\begin{array}{l}\text { "Educação e Trabalho" transformou- } \\
\text { se em "Trabalho e Educação": da } \\
\text { construção da identidade marxista aos } \\
\text { desafios da década de } 90 \text { pelo GTTE } \\
\text { da Anped }\end{array}$ & $\begin{array}{l}\text { Trabalho \& Educação, } \\
\text { v.17, n. 2, maio/ago. } \\
2008 .\end{array}$ \\
\hline 2008 & Anita Handfas & $\begin{array}{l}\text { A trajetória do GT Trabalho e } \\
\text { Educação da Anped: alguns } \\
\text { elementos de análise }\end{array}$ & $\begin{array}{l}\text { Trabalho, Educação e } \\
\text { Saúde, v. 5, n. 3, p. } \\
\text { 375-398, } \\
\text { nov.2007/fev.2008. }\end{array}$ \\
\hline 2009 & $\begin{array}{l}\text { Eunice Trein; Maria } \\
\text { Ciavatta }\end{array}$ & $\begin{array}{l}\text { A historicidade do percurso do GT } \\
\text { Trabalho e Educação: uma análise } \\
\text { para debate }\end{array}$ & $\begin{array}{l}\text { Trabalho, Educação e } \\
\text { Saúde, v. } 7 \text {, } \\
\text { suplemento, p. 15-49, } \\
2009 .\end{array}$ \\
\hline $2010^{*}$ & $\begin{array}{l}\text { Ronaldo Marcos de } \\
\text { Lima Araujo; Gilmar } \\
\text { Pereira da Silva; } \\
\text { Justino de Souza } \\
\text { Junior }\end{array}$ & $\begin{array}{l}\text { As práticas formativas em educação } \\
\text { profissional no estado do Pará: em } \\
\text { busca de uma didática da educação } \\
\text { profissional }\end{array}$ & $\begin{array}{l}\text { Relatório final de } \\
\text { pesquisa - MCT/CNPq } \\
15 / 2007 \text { - Universal }\end{array}$ \\
\hline $2011^{*}$ & $\begin{array}{l}\text { Sueli de Fatima } \\
\text { Ourique de Avila; } \\
\text { Carla Vaz dos Santos } \\
\text { Ribeiro; Denise Bessa } \\
\text { Leda }\end{array}$ & $\begin{array}{l}\text { Trabalho docente na Anped: análise } \\
\text { da produção científica }\end{array}$ & $\begin{array}{l}\text { Inter-Ação, Goiânia, v. } \\
\text { 36, n. 1, p. 63-80, } \\
\text { jan./jun. } 2011 .\end{array}$ \\
\hline 2012 & $\begin{array}{l}\text { Andrey Luise Vieira } \\
\text { Portella; Carina Alves } \\
\text { da Silva Dacoleto }\end{array}$ & $\begin{array}{l}\text { A relação entre Trabalho e Educação } \\
\text { nas produções da ANPEd: o "GT 09" } \\
\text { em foco }\end{array}$ & $\begin{array}{l}4^{\circ} \text { Congresso } \\
\text { Internacional de } \\
\text { Educação, Pesquisa e } \\
\text { Gestão (CIEPG - 2012). } \\
\text { Anais. }\end{array}$ \\
\hline
\end{tabular}

* Trabalhos que consideram outras produções, além daquelas pertinentes ao GT 09.

TrabalhoNecessário - www.uff.br/trabalhonecessario; Ano 13, №20/2015. 
Issn: 1808 - 799X

ano 13 , número $20-2015$

** Material com segunda impressão em 1991.

O quadro apresentado indica um considerável acúmulo de análises sobre o percurso do GT 09 ao longo das últimas décadas, com destaque para a sistematicidade de produções a partir da década de 2000. Não obstante este fato, não se verifica o acolhimento desses estudos na programação do GT na forma de trabalhos encomendados ou de minicursos, o que pode ser justificado pela inexistência de demanda desse tipo de estudo nas reuniões e pela impossibilidade de centralização da identidade do GT entre os assuntos tratados. Entretanto, parece importante encontrar formas de socialização interna das evidências dessas análises. Uma dessas formas poderia ser a definição de uma periodização de trabalhos desse gênero no GT 09; outra, mais imediata, poderia ser a definição de um momento no próximo Intercrítica ${ }^{10}$ para tal socialização.

Decerto que os encontros do GT 09 nas reuniões da Anped são os principais momentos de socialização, debate e reflexão de pesquisadores e demais interessados na área trabalho e educação. Entretanto, pela riqueza das produções da área, expressa, entre outros, pelos 34 grupos de pesquisa representados em 2014 no II Intercrítica, a necessidade de maior tempo para o tratamento de questões teórico-metodológicas e organizativas vem sendo sistematicamente acenada nas reuniões avaliativas do GT 09. Nesse aspecto, a elevação do Intercrítica à condição de evento sistemático do GT parece uma condição inadiável, ao mesmo tempo em que impõe desafios de diversas ordens;

\footnotetext{
${ }^{10} \mathrm{O}$ Intercâmbio Nacional dos Núcleos de Pesquisa em Trabalho e Educação (Intercrítica) é o evento específico do GT 09, objetivando reunir grupos de pesquisa e pesquisadores da área, aprofundar debates teórico-metodológicos, bem como divulgar estudos e tratar de questões organizativas (Reis; Lobo, 2003; UFPA, 2014). O primeiro encontro, organizado pelo Núcleo de Estudos, Documentação e Dados sobre Trabalho e Educação (NEDDATE-UFF), ocorreu em 2002, na Universidade Federal Fluminense, reunindo 11 grupos de pesquisa (Reis; Lobo, 2003). O segundo foi organizado pelo Grupo de Estudos e Pesquisas sobre Trabalho e Educação (GEPTEUFPA) e ocorreu em 2014 (UFPA, 2014), reunindo pesquisadores de 34 grupos/núcleos de pesquisa. Na reunião do GT 09 de 2013, durante a 36a Reunião Anual da Anped, foi estabelecida "[...] uma rotina de encontros nacionais próprios, e em pequena escala, para aprofundar temas que, em virtude do tempo exíguo, não podem ser tratados na ANPEd. Decidiu-se, assim, pela realização, nos anos pares, [...] do INTERCRÍTICA, que deverá ocorrer, de forma itinerante, sempre no mês de agosto [...]" (Rummert, 2014, p. 2).
}

TrabalhoNecessário - www.uff.br/trabalhonecessario; Ano 13, № 20/2015. 


\section{Trabalhonecessário}

Issn: 1808 - 799X

ano 13 , número $20-2015$

a definição da periodicidade bianual das reuniões da Anped alicerça a materialidade para que a demanda se efetive.

Espera-se que as análises sobre o desenho dos temas dos trabalhos encomendados e dos minicursos possam contribuir com o debate dos integrantes do GT 09 e ressalta-se, por fim, que este texto tem caráter meramente indicativo: o vir a ser do GT 09 é tarefa exclusiva do conjunto de seus integrantes.

\section{Referências:}

BOMFIM, Alexandre Maia do. Desvendando a área de trabalho e educação: estudo sobre a produção e os produtores do GT Trabalho e Educação da Anped. 2006. 225 f. Tese (Doutorado em Educação) - Pontifícia Universidade Católica do Rio de Janeiro, Rio de Janeiro, 2006.

KUENZER, Acácia. Educação e trabalho no Brasil: o estado da questão. Brasília: INEP/MEC, 1991.

REIS, Ronaldo Rosas; LOBO, Francisco José Silveira. INTERCRÍTICA Intercâmbio Nacional dos Núcleos de Pesquisa em Trabalho e Educação Relatório Síntese do I Encontro Nacional. Trabalho Necessário, v. 1, n. 1, 2003, p. 1-9.

RUMMERT, Sonia. Relatório da 36a Reunião Anual da ANPEd - Grupo de Trabalho 09 - Trabalho e Educação. Rio de Janeiro: Anped, 2013.

TREIN, Eunice; CIAVATTA, Maria. A historicidade do percurso do GT Trabalho e Educação: uma análise para debate. Trabalho, Educação e Saúde, Rio de Janeiro, v. 7, suplemento, 2009, p. 15-49.

TREIN, Eunice; CIAVATTA, Maria. O percurso teórico e empírico do GT Trabalho e Educação: uma análise para debate. Revista Brasileira de Educação, Rio de Janeiro, n. 24, set./dez. 2003, p. 140-164.

UFPA. Universidade Federal do Pará. Grupo de Estudos e Pesquisas sobre Trabalho e Educação. II INTERCRíTICA - Projeto. Pará: UFPA, 2014.

Recebido em 15 de novembro de 2014 Aprovado em 05 de janeiro de 2015 